\title{
Bluetongue in Europe: vectors, epidemiology and climate change
}

\author{
Anthony Wilson • Philip Mellor
}

Published online: 9 January 2009

(C) Springer-Verlag 2009

Erratum to: Parasitol Res (2008) 103:S69-S77

DOI:10.1007/s00436-008-1053-x

The original version of this article unfortunately contained a mistake. The presentation of Fig. 4 was incorrect. The corrected figure is given below.

Fig. 4 Known distribution of Culicoides imicola in 1999 and 2005 against the observed distribution of BTV outbreaks in southern Europe

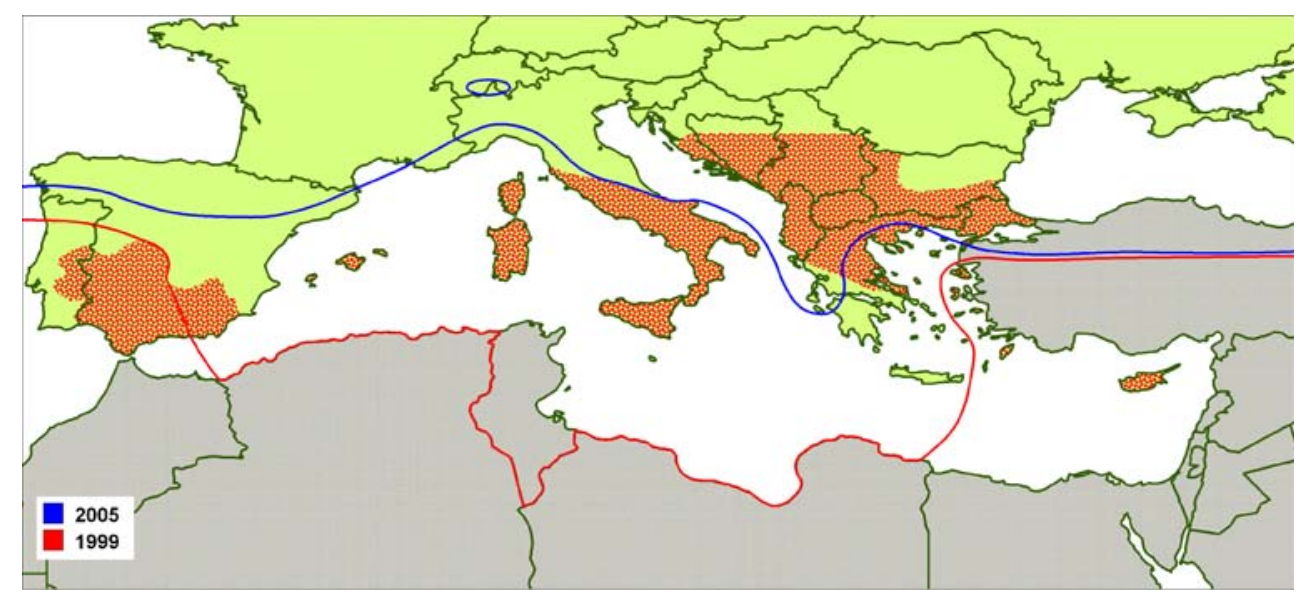

The online version of the original article can be found at http://dx.doi. org/10.1007/s00436-008-1053-x

A. Wilson $(\triangle) \cdot$ P. Mellor

Epidemiology Division, Institute for Animal Health,

Ash Road, Pirbright,

Surrey GU24 0NF, UK

e-mail: iah.bluetongue@bbsrc.ac.uk 